“REVISED-MS \#05-1008”

\title{
Strand displacement of double-stranded DNA by triplex-forming antiparallel purine-hairpins
}

Silvia Coma ${ }^{1}$, Véronique Noé ${ }^{1}$, Ramon Eritja $^{2}$ \& Carlos J. Ciudad ${ }^{1}$

${ }^{1}$ Department of Biochemistry, School of Pharmacy, University of Barcelona, Barcelona, Spain.

${ }^{2}$ Department of Structural Biology. Institut de Biologia Molecular de Barcelona-CSIC, Barcelona, Spain.

Running title: Strand displacement by antiparallel purine-hairpins

* Corresponding author:

C.J. Ciudad, Ph. D.

Dept. Biochemistry

School of Pharmacy

University of Barcelona

Av. Diagonal 643

E-08028 Barcelona, Spain

Email: cciudad@ub.edu

Voice: +34-93-403-4455

Fax: $+34-93-402-4520$ 


\begin{abstract}
We characterize the binding affinity and the thermodynamics of hybridization of triplexforming antiparallel purine-hairpins composed of two antiparallel purine domains linked by a loop directed towards single and double-stranded DNA. Gel retardation assays and melting experiments reveal that a 13 mer purine-hairpin binds specifically and with a $K d$ of $8 \times 10^{-8} \mathrm{M}$ to polypyrimidine single-stranded DNA to form a triple helical structure. Remarkably, we show that purine-hairpins also bind polypurine/polypyrimidine stretches included in a doublestranded DNA of several hundred bp in length. Binding of purine-hairpins to double-stranded DNA occurs by triplex formation with the polypyrimidine strand, causing displacement of the polypurine strand. Since triplex formation is restricted to polypurine/polypyrimidine stretches of double-stranded DNA, we studied the triplex formation between purine-hairpins and polypyrimidine targets containing purine interruptions. We found that a 11 mer purine-hairpin with an adenine opposite to a guanine interruption in the polypyrimidine track binds to single and double-stranded DNA, allowing to expand the possible target sites and to increase the length of purine-hairpins. Thus, when using a 20mer purine-hairpin targeting an interruptioncontaining polypyrimidine target, the binding affinity is increased compared to its $13 \mathrm{mer}$ antiparallel purine-hairpin counterpart. Surprisingly, this increase is much more pronounced than that observed for a tail-clamp purine-hairpin extended up to 20 nucleotides in the Watson-Crick domain only. Thus, triplex-forming antiparallel purine-hairpins can be a potentially useful strategy for both single and double strand nucleic acid recognition.
\end{abstract}




\section{INTRODUCTION}

Triple helices can be formed when short oligonucleotides bind in a sequence-specific manner to the major groove of polypurine/polypyrimidine stretches of double helical DNA forming Hoogsteen pairs with the purines of the Watson-Crick basepairs (Felsenfeld and Rich 1957; Le Doan et al. 1987; Moser and Dervan 1987). Triplex forming oligonucleotides (TFOs) are classified, at least, into three main categories that differ in their sequence composition and its orientation with respect to the polypurine Watson-Crick target strand. In the first class, the pyrimidine motif, the polypyrimidine third strand ( $\mathrm{C}$, T-oligonucleotide) binds in a parallel orientation to the polypurine strand of the duplex by Hoogsteen hydrogen bonds, forming $T . A^{*} T$ and $C . G^{*} C^{+}$triplices. For greatest stability, cytosine must be protonated making these triplexes pH dependent (Husler and Klump 1995; Lavelle and Fresco 1995; Asensio et al. 1998). The incorporation of 5-methylcytosines instead of cytosines in such TFOs increases the stability of triplexes at physiological pH (Lee et al. 1984; Maher et al. 1989). In the second class, the purine motif, the polypurine third strand (G,A-oligonucleotide) binds in an antiparallel orientation to the polypurine strand of the duplex by reverseHoogsteen hydrogen bonds, forming T.A*A and C.G*G triplices. These TFOs bind to the duplex at near neutral $\mathrm{pH}$ and often require a high divalent cation concentration (FrankKamenetskii and Mirkin 1995; Francois et al. 2000). In the third class, the third strand (G,T.oligonucleotide) binds either in a parallel or antiparallel orientation to the polypurine strand of the duplex, depending on the base sequence, forming T.A*T and C.G*G triplices (Sun et al. 1991).

Although TFOs are promising tools for gene therapy (Chan and Glazer 1997; Giovannangeli and Helene 1997; Casey and Glazer 2001), new strategies to increase the stability and the binding affinity of the oligonucleotide involved in triplex formation are being investigated. In these novel approaches, the triple helical structure is formed when a singlestranded DNA target binds to a duplex oligonucleotide (Kool 1996; Kool 1997). Two examples of these novel oligonucleotides are i) hairpin oligonucleotides, which consist of two 
strands linked by a loop, and ii) circular oligonucleotides, with two binding domains linked in a circular way. These molecules bind to single-stranded DNA or RNA sequences with considerably greater affinity and sequence-selectivity than those seen for linear oligonucleotides. Most structural studies on triplex formation using hairpin and circular oligonucleotides focused on parallel helices (Plum and Breslauer 1995; Kool 1996; Kool 1997). However, in the biomedical field, antiparallel triplexes using duplex oligonucleotides are more promising than parallel structures, since the formation of antiparallel triplex is $\mathrm{pH}$ independent (Vasquez et al. 1995; Faucon et al. 1996; Mills et al. 2002). In this regard, several groups described the ability of purine-hairpins to form an antiparallel triple helical structure with a polypyrimidine single-stranded targets (Wang 1994; Vo et al. 1995; Mills et al. 1999; Avino et al. 2003; Nadal et al. 2005). These triplex-forming antiparallel purinehairpins consist of two antiparallel purine domains linked by a loop, in which one domain binds by Watson-Crick base pairing to the polypyrimidine single-stranded target (WatsonCrick domain), and the other binds by reverse-Hoogsteen base pairing to the newly formed duplex (reverse-Hoogsteen domain).

Until now, this novel strategy for antiparallel pyr.pur*pur triplex formation is restricted to the binding of antiparallel purine-hairpins to single-stranded targets. In this study, we addressed the ability of antiparallel purine-hairpins to bind polypyrimidine sequences when they are part of a double-stranded DNA. Triplex formation is restricted to polypurine/polypyrimidine stretches of double helical DNA. Therefore, in an effort to expand the number of possible target sites and to increase the purine-hairpin length, we also studied triplex formation between purine-hairpins and interruption-containing polypurine/polypyrimidine DNA. In this work we show that purines can be included in the polypyrimidine target sequence with surprising affinity, thus increasing the general utility of these probes as a strategy for both single and double strand nucleic acid recognition. 


\section{MATERIALS AND METHODS}

Oligodeoxynucleotides. Unmodified oligodeoxynucleotides were synthesized by Sigma-Genosys $(0.05 \mu \mathrm{mol}$ scale). Purity was checked by gel electrophoresis. The concentration of oligodeoxynucleotides was verified by measuring the absorbance $(260 \mathrm{~nm})$ at $25^{\circ} \mathrm{C}$. All concentrations were expressed in strand molarity. The sequences of the oligodeoxynucleotides are listed in Table 1.

UV absorption studies. Melting experiments were performed in buffer containing 40 $\mathrm{mM} \mathrm{MgCl} 2,100 \mathrm{mM} \mathrm{NaCl}$ and $50 \mathrm{mM}$ HEPES, $\mathrm{pH}$ 7.2. The mixture was prepared using a 1:1 ratio of purine-hairpin and polypyrimidine single-stranded DNA (2 $\mu \mathrm{M}$ in each strand). The solutions were heated at $90^{\circ} \mathrm{C}$ in a water bath and allowed to cool slowly to room temperature before performing the melting experiments.

Melting studies (absorbance versus temperature) were carried out in $1 \mathrm{~cm}$ path length quartz cells using a spectrophotometer with a temperature controller. Absorbance $(260 \mathrm{~nm})$ was monitored while temperature was either raised or decreased at a rate of $0.5^{\circ} \mathrm{C} / \mathrm{min}$. In all cases the cooling and heating profiles were superimposable. No hysteresis was observed.

Thermodynamic analysis of triplex formation. Melting temperatures $(\mathrm{Tm})$ and free energy values $(\Delta G)$ were derived by computer-fitting the denaturation data, using the MeltWin 3.5 software. Thermodynamic data were calculated as the mean of three independent melting experiments. Uncertainties in $\mathrm{Tm}$ values and in free energies are estimated at $+/-1.0^{\circ} \mathrm{C}$ and $+/-10 \%$, respectively. Free energy values are given at $37^{\circ} \mathrm{C}$.

Preparation of polypurine/polypyrimidine duplexes. Twenty-five $\mu \mathrm{g}$ of each single-stranded polypurine and polypyrimidine oligodeoxynucleotides were mixed in a 150 $\mathrm{mM} \mathrm{NaCl}$ solution. After incubation at $90^{\circ} \mathrm{C}$ for 5 minutes, solutions were allowed to cool slowly to room temperature. The duplex was purified in a non-denaturing $20 \%$ polyacrylamide gel and quantified by absorbance at $260 \mathrm{~nm}$ at $25^{\circ} \mathrm{C}$.

Preparation of PCR fragments. Genomic DNA from CHO cells was extracted using a buffer containing $1 \mathrm{mM}$ EDTA, $0.4 \mathrm{M} \mathrm{NaCl}, 0.1 \%$ SDS and $10 \mathrm{mM}$ Tris, $\mathrm{pH}$ 7.4. The sample 
was deproteinized by $200 \mu \mathrm{g} / \mathrm{mL}$ proteinase $\mathrm{K}$ (Roche) at $37^{\circ} \mathrm{C}$ for 2 hours and extracted twice with 50:50 phenol:chloroform. Genomic DNA was precipitated with ethanol. After treatment with $40 \mu \mathrm{g} / \mathrm{mL}$ RNAsa for 2 hours at $37^{\circ} \mathrm{C}$, genomic DNA was extracted twice with 50:50 phenol:chloroform and precipitated with ethanol.

A standard $50 \mu \mathrm{l} \mathrm{PCR} \mathrm{mixture} \mathrm{contained} 1 \mu \mathrm{g}$ genomic DNA, $5 \mu \mathrm{L}$ of $10 \times$ PCR buffer (Mg2+-free), $1.5 \mathrm{mM} \mathrm{MgCl}_{2}, 0.2 \mathrm{mM}$ dNTPs, 1.5 units of Taq polymerase (Ecogen) and 500 ng of each of the two primers. The primers used were 5'-CAATGGGTGTACAATTAAGTC-3' and 5'-AACTTGAAGTCAATCAGCAAG-3' (for the PCR fragment of 152 bp in length) and 5'GTCATGTGTCTTCAATGGGTG-3' and 5'-TCTAAAGCCAACACAAGTCCC-3' (for the PCR fragment of $227 \mathrm{bp}$ in length) corresponding to the Chinese hamster dihydrofolate reductase gene. Both PCR fragments contained the polypurine/polypyrimidine target in the center of the duplexes. The PCR reaction was performed under standard conditions: after a 3-minute denaturation at $94^{\circ} \mathrm{C}$, each cycle consisted of denaturation at $92^{\circ} \mathrm{C}$ for 30 seconds, primer annealing at $59^{\circ} \mathrm{C}$ for 1 minute and primer extension at $72^{\circ} \mathrm{C}$ for 1 minute. After 35 cycles, a final extension at $72^{\circ} \mathrm{C}$ for 7 minutes was performed. The amplified DNA fragments were purified in a non-denaturing $5 \%$ polyacrylamide gel and extracted with $400 \mu \mathrm{l}$ of $1 \mathrm{mM}$ EDTA, $0.5 \mathrm{M}$ ammonium acetate and $0.1 \% \mathrm{SDS}$, overnight at $37^{\circ} \mathrm{C}$ with shaking. Then, the PCR fragments were precipitated with ethanol and its content in genomic DNA was determined by measuring the absorbance $(260 \mathrm{~nm})$ at $25^{\circ} \mathrm{C}$. Purity of the fragments was checked by gel electrophoresis.

Oligodeoxynucleotide labelling. One hundred ng of single or double-stranded oligodeoxynucleotide was 5 '-end-labeled with $\left[\gamma^{32} \mathrm{P}\right]-\mathrm{ATP}$ by T4 polynucleotide kinase (New England BioLabs) in a $10 \mu \mathrm{L}$ reaction mixture, according to the manufacturer's protocol. After incubation at $37^{\circ} \mathrm{C}$ for 1 hour, $90 \mu \mathrm{L}$ of TE buffer ( $1 \mathrm{mM}$ EDTA and $10 \mathrm{mM}$ Tris, $\mathrm{pH} 8.0$ ) were added to the reaction mixture, which was subsequently filtered through a Sephadex G-50 spin-column (Pharmacia, Uppsala, Sweden) to eliminate the unlabeled $\left[\gamma^{32} \mathrm{P}\right]-\mathrm{ATP}$. Purinehairpins (100 ng) were also 5'-end-labeled using the same conditions. 
Electrophoretic mobility shift assay (EMSA). Triplex formation was analyzed by incubating radiolabeled single or double-stranded DNA (10 nM strand concentration; 20,000 $\mathrm{cpm}$ ) in the presence or absence of unlabeled purine-hairpin (10 nM - $50 \mu \mathrm{M}$ strand concentration) in a buffer containing $40 \mathrm{mM} \mathrm{MgCl}$ (unless otherwise noted), $100 \mathrm{mM} \mathrm{NaCl}$ and $50 \mathrm{mM}$ HEPES, $\mathrm{pH}$ 7.2. The analysis was also performed using radiolabeled purinehairpin (10 nM strand concentration; 20,000 cpm) and increasing concentrations of unlabeled double-stranded DNA (0.1 - $5 \mu \mathrm{M}$ duplex concentration). Binding reactions $(20 \mu \mathrm{L})$ were incubated for periods of time ranging from $10 \mathrm{~min}$ to $16 \mathrm{~h}$ at $37^{\circ} \mathrm{C}$ before running the electrophoresis. To check for specificity, the unlabeled single-stranded competitor was mixed with the specific radiolabeled single-stranded oligonucleotide prior to purine-hairpin addition. Electrophoresis was performed on a non-denaturing $12 \%$ polyacrylamide gel containing 10 $\mathrm{mM} \mathrm{MgCl} 2,5 \%$ glycerol and $50 \mathrm{mM}$ HEPES, $\mathrm{pH}$ 7.2. Gels were run for $3-4 \mathrm{~h}$ at $190 \mathrm{~V}$ at $4^{\circ} \mathrm{C}$, dried and analyzed on a Storm 840 Phosphorimager (Molecular Dynamics). Apparent dissociation constants, $K d$, for triplex formation are estimated as the added purine-hairpin concentration required to shift $50 \%$ of the radiolabel from the single-strand state to a triplex state following $16-\mathrm{h}$ incubations at $37^{\circ} \mathrm{C}$. All binding assays were carried out in triplicate. 


\section{RESULTS}

Design of triplex-forming antiparallel purine-hairpins. We searched for polypurine/polypyrimidine sequences within the Chinese hamster dihydrofolate reductase gene (dhfr gene) with a length ranging between $10-20$ bases. We selected two stretches in the dhfr gene. The sequence located within exon 6 contains 13 contiguous purines/pyrimidines, which can be extended to 20 bases in length if three interruptions are taken into account. The stretch placed within exon 1 contains 11 purines/pyrimidines with only one interruption. Triplex-forming antiparallel purine-hairpins used in this study were composed of two antiparallel purine domains, a Watson-Crick domain and a reverseHoogsteen domain, both of the same length, linked by a penthathymidine loop. They were designed to form a triple helical structure by binding the polypyrimidine strand by WatsonCrick base pairing. Additionally, tail-clamp purine-hairpins with the Watson-Crick domain extended were also used. Control oligonucleotides, bearing a scrambled reverse-Hoogsteen domain or without the reverse-Hoogsteen domain, were designed to bind polypyrimidine strand forming a duplex structure. The sequences of the oligodeoxynucleotides used in this study are listed in Table 1.

\section{Antiparallel purine-hairpins specifically bind polypyrimidine single-stranded}

DNA. Binding between hairpin6 (directed to a 13 nt polypurine/polypyrimidine stretch in the exon 6 of the dhfr gene) and its polypyrimidine single-stranded DNA target (20py6 singlestranded oligonucleotide) was confirmed using gel retardation assays. Efficiency of binding was measured after a 16-h incubation of radiolabeled polypyrimidine single-stranded DNA with increasing amounts of unlabeled hairpin6 at $37^{\circ} \mathrm{C}$, using $\mathrm{Mg}^{2+}$-containing polyacrylamide gels which maintained triplex DNA structure during electrophoresis. As shown in figure 1A, complete binding was observed in all reactions containing hairpin6 (1-50 $\mu \mathrm{M}$ strand concentration). The time required for binding was also measured. Ten minutes were sufficient to obtain optimal binding between hairpin6 ( $1 \mu \mathrm{M}$ strand concentration) and its 
single-stranded DNA target, and after very long periods of incubation no significant decrease in binding was observed (Figure 1B).

Sequence-specific binding of hairpin6 was studied using a specific and a non-specific oligonucleotide as competitors. As expected, the retarded band corresponding to the binding between hairpin6 and its polypyrimidine single-stranded DNA target was unaffected by the presence of the unlabeled non-specific competitor. In contrast, using 100 -fold unlabeled specific target a decrease in binding was observed (Figure 1C).

To test the levels of magnesium required for hairpin6 to bind its polypyrimidine singlestranded DNA target, a range of $\left[\mathrm{MgCl}_{2}\right]$ was used in EMSA assays. As shown in figure $1 \mathrm{D}$, a high degree of binding was detectable even when hairpin6 was incubated with its polypyrimidine single-stranded DNA target in the presence of $1 \mathrm{mM} \mathrm{MgCl}_{2}$.

These results indicated that hairpin6 formed a very sequence-specific structure with its polypyrimidine single-stranded DNA target and that the formation was fast and stable.

\section{Antiparallel purine-hairpins bind polypurine/polypyrimidine double-stranded}

DNA. The ability of hairpin6 to bind its polypurine/polypyrimidine double helical DNA target was also investigated. After incubation of radiolabeled hairpin6 with its unlabeled polypurine/polypyrimidine double-stranded DNA target (20pu6/20py6 duplex), a retarded band was observed. Increasing concentrations of polypurine/polypyrimidine double-stranded DNA target (0.1-5 $\mu \mathrm{M}$ duplex concentration) led to an increase in the formation of the shifted band after a 16-h incubation, showing a $\mathrm{Kd}$ of $3 \times 10^{-7} \mathrm{M}$ (Figure $2 \mathrm{~A}$ ). Binding was measured after various incubation times. As shown in figure 2B, very short incubation times (10 min) were sufficient to form full binding between hairpin6 and its polypurine/polypyrimidine doublestranded DNA target (1 $\mathrm{MM}$ duplex concentration), and after very long periods of incubation no significant decrease in binding was observed. Interestingly, hairpin6 was also able to bind its polypurine/polypyrimidine double-stranded DNA target when it was included in the center of DNA duplexes of several hundred bp in length (152 bp and $227 \mathrm{bp}$ ). As shown in figure $2 \mathrm{C}$, increasing concentrations of polypurine/polypyrimidine double-stranded DNA target (0.1$1 \mu \mathrm{M}$ duplex concentration) led to an increase in the formation of the shifted band after an 
incubation of $16 \mathrm{~h}$. Binding was detectable even when hairpin6 was incubated with long DNA duplexes (152 and $227 \mathrm{bp}$ ) containing the polypurine/polypirimidine target in the presence of $1 \mathrm{mM} \mathrm{MgCl}_{2}$ (Figure 2D).

The composition of such retarded band was investigated using radiolabeled doublestranded DNA and unlabeled hairpin6. As shown in figure 3A, after incubation of hairpin6 (0.1 $\mathrm{\mu M}$ strand concentration) with its radiolabeled polypurine/polypyrimidine double-stranded DNA target (radiolabeled in the polypyrimidine target strand) a retarded band (lane 3a) of the same size of the triplex formed between hairpin6 and its polypyrimidine single-stranded DNA target (lane 7a) was observed. Thus, binding of hairpin6 to its polypurine/polypyrimidine double-stranded DNA target resulted in the formation of a triple helical structure between hairpin6 and the polypyrimidine single strand of the duplex DNA. Displacement of the polypurine strand of the DNA duplex was confirmed using i) a duplex radiolabeled in the polypurine strand and ii) a duplex radiolabeled in both strands. Incubation of hairpin6 with the radiolabeled-polypurine duplex resulted in the appearance of a band (lane 4c) of the same size of the single polypurine strand (lane $5 \mathrm{c}$ ). Incubation of hairpin6 with the duplex radiolabeled in both strands resulted in the formation of a retarded band (lane $2 a$ ) corresponding to the binding of hairpin6 with the polypyrimidine strand (lane $7 a$ ), and the appearance of a band (lane 2c) of the same size of the single polypurine strand (lane $5 \mathrm{c}$ ). Figure 3B depicts a diagram showing the displacement of the polypurine strand upon triplex formation between hairpin 6 and the polypyrimidine strand of the polypurine-polypyrimidine duplex.

Effect of the reverse-Hoogsteen domain on the binding of antiparallel purinehairpins to single and double-stranded DNA. EMSA were used to study the contribution of the reverse-Hoogsteen domain on the binding of hairpin6 to its polypyrimidine singlestranded DNA target (20py6 single-stranded oligonucleotide) or to its polypurine/polypyrimidine double-stranded DNA target (20pu6/20py6 duplex). As shown in figure $4 \mathrm{~A}$, the percentage of binding between hairpin6 and its polypyrimidine single-stranded DNA target gradually increased depending on the concentration of hairpin6, showing a $K d$ of 
$8 \times 10^{-8} \mathrm{M}$. In contrast, control oligonucleotides not able to form a triple helical structure with the polypyrimidine strand, either bearing a scrambled reverse-Hoogsteen domain (hairpin6scrambled) or containing the Watson-Crick domain only (Watson-Crick6), produced no more than $40 \%$ of binding even when used at $1 \mu \mathrm{M}$. This supports that a triple helical structure is formed between hairpin6 and its polypyrimidine single-stranded DNA target.

The formation of a triple helical structure is usually accompanied by hypochromism at $260 \mathrm{~nm}$. Thus, the relative stability of the triple helical structure formed between hairpin 6 and its polypyrimidine single-stranded DNA target (33py6 single-stranded oligonucleotide) was also monitored by measuring the change in absorbance as a function of the temperature at $260 \mathrm{~nm}$. A melting temperature $(T m)$ of $63.3^{\circ} \mathrm{C}$ was obtained for hairpin6 corresponding to the triplex status, whereas control oligonucleotides (hairpin6-scrambled or Watson-Crick6) showed a decrease in the $T m$ of 8.2 and $5.6^{\circ} \mathrm{C}$, respectively (Figure 4B), corresponding to the duplex status. In all cases, one single transition was observed which characterized the conversion from the bound complex to a random coil. Melting profiles gave sigmoidal curves indicating a cooperative transition, and the data were fitted to a two-state model for the bound complex to free oligomers transition using the MeltWin 3.5 software (McDowell and Turner 1996). $\Delta G$ of formation for the triple helical structure between hairpin6 and its polypyrimidine single-stranded DNA target was $-18.4 \mathrm{kcal} / \mathrm{mol}$. Control oligonucleotides (hairpin6-scrambled or Watson-Crick6) gave lower $\Delta G$ values corresponding to Watson-Crick duplex formation (Figure 4B). In our study we did not observed any self-associated structure for hairpin6. A monotonous behavior of the absorbance of hairpin6 as a function of temperature was obtained (data not shown),

Interestingly, only hairpin6 was able to bind its polypurine/pyrimidine double-stranded DNA target. No binding was obtained when using control oligonucleotides bearing a scrambled reverse-Hoogsteen domain (hairpin6-scrambled) or containing the Watson-Crick domain only (Watson-Crick6), under the same conditions (Figure 5A). Binding of hairpin6 to its polypurine/polypyrimidine double-stranded DNA target was also observed when the polypurine/polypyrimidine stretch was included in a DNA duplex of 49 nt in length 
(49pu6/49puy6 duplex). In contrast, hairpin6-scrambled only produced a very fainted retarded band in the presence of the 49nt double-stranded DNA target, even when added at $5 \mu \mathrm{M}$ (Figure 5B).

These results demonstrated the contribution of the reverse-Hoogsteen domain of the purine-hairpin on the triple helical structure formed between hairpin6 and its polypyrimidine DNA target even when included in a double-stranded DNA target.

\section{Effect of an interruption in the polypurine/polypyrimidine sequence on triplex} formation with antiparallel purine-hairpins. EMSA and UV melting experiments were used to study the binding of hairpin 1 directed to a $11 \mathrm{nt}$ purine/pyrimidine stretch in exon 1 of the dhfr gene bearing one-base interruption. We designed three hairpins 1 that differed on the base opposite to the guanine interruption in the polypyrimidine strand. Hairpin1-AA contained an adenine in both domains of hairpin1. Hairpin1-GG contained a guanine in both domains of hairpin1. Hairpin1-CG contained a cytosine in the Watson-Crick domain and a guanine in the reverse-Hoogsteen domain of the hairpin1. Thus, hairpin1-AA and hairpin1-GG contained a base-pair mismatch in the Watson-Crick domain, while hairpin1-CG contained a base-pair interruption in the reverse-Hoogsteen domain (Figure 6A).

The efficiency of binding of such hairpins1 was studied using gel retardation assays. As shown in figure 6A binding to polypyrimidine single-stranded DNA (28py1 single-stranded oligonucleotide) after a $16-\mathrm{h}$ incubation at $37^{\circ} \mathrm{C}$ was higher for hairpin1-AA than for hairpin1CG or hairpin1-GG. The percentage of binding increased gradually with the concentration of hairpin1-AA, showing a $K d$ of $6 \times 10^{-8} \mathrm{M}$. When used at $1 \mu \mathrm{M}$, hairpin1-CG produced $80 \%$ of triplex formation $\left(K d\right.$ of $\left.2 \times 10^{-7} \mathrm{M}\right)$, while hairpin1-GG only achieved $15 \%\left(K d\right.$ of $\left.>10^{-6} \mathrm{M}\right)$ in the same conditions. Thermodynamic data using UV melting experiments suggested that hairpin1-AA and hairpin1-CG formed the most stable triple helical structure with its polypyrimidine single-stranded DNA target (28py1 single-stranded oligonucleotide), whereas hairpin1-GG formed the less stable triple helical structure (Figure 6B). Interestingly, both hairpin1-AA and hairpin1-CG bound with more affinity to its polypurine/polypyrimidine double-stranded DNA target (28pu1/28py1 duplex) than hairpin1-GG (Kd of $7 \times 10^{-7} \mathrm{M}, 10^{-6} \mathrm{M}$ 
and $>10^{-6} \mathrm{M}$, respectively) (Figure $6 \mathrm{C}$ ). In figure $6 \mathrm{D}$ a diagram showing the $G . A^{*} A$ triplex that might be formed using hairpin1-AA is depicted. The 6-keto and $\mathrm{N}-1-\mathrm{H}$ groups of guanine could participate in hydrogen bounds in the same way as the 4-keto and $\mathrm{N}-1-\mathrm{H}$ of thymidine, and for this reason the G.A*A triplex obtained could be similar to the T.A*A triplex formed in an antiparallel triplex.

\section{Recognition of polypurine/polypyrimidine sequence by extended and tailed} purine-hairpins. To improve the affinity of hairpin 6 we designed two kind of hairpin6 longer than $13 \mathrm{nt}$, i) tail-hairpin6, a tail-clamp purine-hairpin with only the Watson-Crick domain extended up to $20 \mathrm{nt}$, and ii) hairpin6-20, a purine-hairpin of $20 \mathrm{nt}$ in both domains of the hairpin (reverse-Hoogsteen and Watson-Crick domains) containing three adenines opposite to the three interruptions (two guanines and one adenine) in the polypyrimidine target strand (Figure 7A).

Triplex formation between tail-hairpin6 or hairpin6-20 and its polypyrimidine singlestranded DNA target (33py6 single-stranded oligonucleotide) was confirmed using gel retardation assays. Increasing concentrations of unlabeled tail-hairpin6 or hairpin6-20 (0.01-1 $\mu \mathrm{M}$ strand concentration) led to increased triplex formation after a 16-h incubation with its radiolabeled polypyrimidine single-stranded DNA target. As shown in figure 7A, hairpin6-20 bound to its single-stranded DNA target with higher affinity than tail-hairpin6 ( $K d$ of $4 \times 10^{-8} \mathrm{M}$ and $6 \times 10^{-8} \mathrm{M}$, respectively). Thermodynamic data using UV melting experiments confirmed that hairpin6-20 formed a more stable triple helical structure with its polypyrimidine singlestranded DNA target (33py6 single-stranded oligonucleotide) than tail-hairpin6, with a difference in $\Delta G$ of $-4 \mathrm{kcal} / \mathrm{mol}$ (Figure 7B).

However, a major difference between hairpin6-20 and tail-hairpin6 was observed when studying the time required for binding with its double-stranded DNA target (33pu6/33py6 duplex). As shown in figure 7C, hairpin6-20 bound to its double-stranded DNA target much faster than tail-hairpin6. Very short incubation times (10 $\mathrm{min}$ ) were sufficient to form full binding between hairpin6-20 and its polypurine/polypyrimidine double-stranded DNA 
Coma

target ( $1 \mu \mathrm{M}$ duplex concentration). In contrast, an incubation of 16 hours was needed to obtain a complete triplex formation with tail-hairpin6 in the same conditions. 


\section{DISCUSSION}

\section{Binding of antiparallel purine-hairpins to polypurine/polypyrimidine double-}

stranded DNA. In this work, we studied the interaction between antiparallel purine-hairpins and polypurine/polypyrimidine DNA targets. As a model we used two antiparallel purinehairpins (hairpin1 and hairpin6) directed to two purine/pyrimidine DNA stretches present in exon 1 and exon 6 of the Chinese hamster dhfr gene, respectively. We tested such purinehairpins for their ability to bind single and double-stranded DNA forming a triple helical structure. Using binding assays and UV melting experiments we monitored the binding properties and the stability of the binding between hairpin6 (13 nt in length) and its polypyrimidine single-stranded DNA target. It was found that hairpin6 binds its polypyrimidine single-stranded DNA target significantly more strongly than the achieved by simple WatsonCrick recognition ( $\mathrm{Kd}$ of $8 \times 10^{-8} \mathrm{M}$ and $>10^{-6} \mathrm{M}$, respectively) as a result of the increases in $\mathrm{Tm}$ of $6-8^{\circ} \mathrm{C}$ and in $\Delta G$ of $-4-6 \mathrm{kcal} / \mathrm{mol}$. This supports that a triple helical structure is formed between hairpin6 and its polypyrimidine single-stranded DNA target. This binding is sequence-specific, as an unrelated competitor was unable to interfere with target recognition. Moreover, we also demonstrated the ability of hairpin6 to bind its polypurine/polypyrimidine double-stranded DNA target rapidly and with a $\mathrm{Kd}$ of $3 \times 10^{-7} \mathrm{M}$. Interestingly, binding of hairpin6 to double-stranded DNA can occur even if the polypurine/polypyrimidine doublestranded DNA target is included in the center of DNA duplexes of several hundred bp in length. Hairpin6 forms a triple helical structure with the polypyrimidine single strand of the duplex DNA displacing the polypurine strand. No binding or strand displacement was obtained when using control oligonucleotides bearing a scrambled reverse-Hoogsteen domain (hairpin6-scrambled) or containing the Watson-Crick domain only (Watson-Crick6), under the same conditions. This represents the first observation of the ability of non-modified oligonucleotides to bind double helical DNA by triplex formation producing strand displacement. Until now, only peptide nucleic acids (PNAs), oligonucleotides modified in the sugar-phosphate backbone, were reported to interact with duplex DNA via a strand- 
displacement reaction involving P-loops formation (Nielsen et al. 1991; Cherny et al. 1993; Demidov et al. 1993; Peffer et al. 1993). Although PNAs can form remarkably strong and sequence-specific complexes with duplex DNA, they are modified oligonucleotides with uncharged peptidelike backbone, more expensive and difficult to synthesize than nonmodified hairpin oligonucleotides (Nielsen 1993).

Moreover, our results revealed that antiparallel purine-hairpins are a promising tool for sequence-specific targeting within the cell since the in vitro experiments were performed maintaining several important parameters, such as temperature, $\mathrm{pH}$ and salt concentration, close to the physiological conditions. Interestingly, EMSA assays reveled that purine-hairpins bind polypurine/polypyrimidine stretches included in a double-stranded DNA of several hundred bp even if $1 \mathrm{mM} \mathrm{Mg}^{2+}$ concentration is used in the binding reactions. In addition to the notable binding properties of purine-hairpins to form triplex structures under physiological conditions, they present several potential advantages, such as better nuclease resistance since duplex oligonucleotides are not substrates for degradation by exonucleases (Kool 1996). Unfortunately, G-rich oligonucleotides are able to form undesired intra- or intermolecular structures involving the formation of $G$ tetrads (Cheng et al. 1998). Thus, the ability of antiparallel purine-hairpins to form a triple helical structure with its polypurine/polypyrimidine DNA target may be reduced by its ability to form G-quartets. In our study, we did not observe any self-associated structure for hairpin6. A monotonous behavior of the absorbance of hairpin 6 as a function of temperature was obtained, and no anomaly of migration was observed on a non-denaturing gel. It is known that such intra- or intermolecular structures are stabilized by physiological concentrations of monovalent cations, such as potassium, making this self-association likely in vivo (Basu and Wickstrom 1997; Jing et al. 2002). Interestingly, in our experiments, the ability of hairpin6 to bind to its single or double-stranded DNA target to form a triple helical structure was not reduced neither in the presence of physiological concentrations of potassium nor in buffers containing large concentrations of potassium (data not shown). The absence of self-association for such 
hairpin6 is probably the result of dispersion of guanines in the oligonucleotide and such sequences are not favorable to guanine quadruplex formation.

\section{Binding of antiparallel purine-hairpins to interruption-containing} polypurine/polypyrimidine DNA. Design of antiparallel purine-hairpins is restricted to polypurine/polypyrimidine stretches of DNA duplex, limiting its use for biomedical applications (Goni et al. 2004). Since the presence of purines in the polypyrimidine target strand leads to a strong triplex destabilization (Kukreti et al. 1998), we studied the effect of one interruption on the triplex formation between antiparallel purine-hairpins and interruptioncontaining polypurine/polypyrimidine DNA targets. We demonstrated that binding of hairpin1 (11 nt in length) to its polypurine/polypyrimidine DNA target can occur in the presence of one guanine interruption within the polypyrimidine stretch. The best results were obtained when, opposite the guanine interruption, an adenine was placed in both domains of hairpin1. This hairpin1-AA shows an increase in efficiency of triplex formation of 20-fold and 2-fold as compared to hairpin1-GG and hairpin1-CG, respectively. It is interesting to note that hairpin1AA, not only interacts to its single-stranded DNA target to form a triplex structure, but also binds its double-stranded DNA target to form the triplex structure with the polypyrimidine strand. Moreover, the hairpin we developed avoids the necessity of using non-natural nucleotides in front of the guanine-interruption (Huang et al. 1996; Obika et al. 2000; Guianvarc'h et al. 2001) and suggests the formation of a new antiparallel G.A*A triplex, similar to the T.A*A triplex formed in antiparallel triplexes. The characterization of this new triplex could be the subject of study in a future work.

With the information gathered using hairpin1-AA, we designed a hairpin6 against the exon 6 of the dhfr gene with an increased length of up to 20 nt but containing 3 adenines interruptions in both domains (hairpin6-20), showing higher affinity to its single and doublestranded polypurine/polypyrimidine DNA target than its 13 mer purine-hairpin counterpart. Until now, several groups investigated the use of PNAs containing a mixed base extension of the Watson-Crick polypyrimidine strand (tail-clamp PNAs), to extend the recognition of the PNAs (Lohse et al. 1999; Demidov et al. 2002; Bentin et al. 2003; Kaihatsu et al. 2003). 
Interestingly, our results showed that hairpin6-20, with both domains of the purine-hairpin extended up to $20 \mathrm{nt}$, binds with higher affinity to its single and double-stranded DNA target than tail-hairpin6 (a tail-clamp purine-hairpin containing only the Watson-Crick domain extended with mixed base sequences up to $20 \mathrm{nt}$ ). It is interesting to note that the pyrimidine target in the double-stranded DNA was not present at the end for either tail-hairpin6 and hairpin6-20. This characteristic would allow the use of these purine-hairpins in relevant biological experiments where the target is in the center of a long DNA duplex. Using both methodologies, we were able to design antiparallel purine-hairpins that bind single and double-stranded DNA targets and exhibit high sequence-specific recognition of interruptioncontaining polypurine/polypyrimidine DNA targets. This should help in increasing the number of possible DNA targets susceptible to be bound by antiparallel purine-hairpins with high specificity.

In summary, we show that in the sequence context of exon 1 and exon 6 of the Chinese hamster dhfr gene, triplex formation is possible using antiparallel purine-hairpins. Until now, only TFOs targeted to the human dhfr promoter were used (Blume et al. 1992; Gee et al. 1992). Our results indicate that it is possible to design extended and tailed purinehairpins for a given polypyrimidine strand even if it contains purine interruptions. Moreover, antiparallel purine-hairpins can be used as a potentially useful strategy for both single and double strand nucleic acid recognition. In common with TFOs, purine-hairpins could be used for antigene strategy by modulating gene activity in vivo at the transcriptional level, with the advantage to be more stable since they are more resistant to nucleases. In addition, it has to be stressed the ability of these purine-hairpins to provoke strand displacement of doublestranded DNA. This characteristic would add additional activities to these purine-hairpins compared to TFOs, such as: i) to prevent the access of DNA-binding proteins to doublestranded DNA in antigene strategy, ii) to direct compounds to specific regions of the doublestranded DNA and iii) to facilitate homologous recombination upon opening the two strands in experiments attempting to repair DNA at the endogenous locus. Moreover, purine-hairpins 
Coma

could also be used as antisense strategy to inhibit gene expression, with the benefit to be more stable than aODN, and with the possibility of binding folded RNA with secondary double-stranded structures. 
Coma

\section{ACKNOWLEDGMENTS}

This research was supported by grants SAF02-0363 and SAF05-0247 from the "Comisión Interministerial de Ciencia y Tecnología" and 2001SGR141 from the "Comissionat d'Universitats i Recerca (CUR)". S.C. is the recipient of a postgraduate fellowship from the Spanish Ministry of Education. We thank Jordi Robles from University of Barcelona for his help with the use of MeltWin software. 


\section{REFERENCES}

Asensio, J.L., A.N. Lane, J. Dhesi, S. Bergqvist, and T. Brown. 1998. The contribution of cytosine protonation to the stability of parallel DNA triple helices. $J$ Mol Biol 275: 811 22.

Avino, A., E. Cubero, C. Gonzalez, R. Eritja, and M. Orozco. 2003. Antiparallel triple helices. Structural characteristics and stabilization by 8-amino derivatives. J Am Chem Soc 125: 16127-38.

Basu, S. and E. Wickstrom. 1997. Temperature and salt dependence of higher order structure formation by antisense c-myc and c-myb phosphorothioate oligodeoxyribonucleotides containing tetraguanylate tracts. Nucleic Acids Res 25: 1327-32.

Bentin, T., H.J. Larsen, and P.E. Nielsen. 2003. Combined triplex/duplex invasion of doublestranded DNA by "tail-clamp" peptide nucleic acid. Biochemistry 42: 13987-95.

Blume, S.W., J.E. Gee, K. Shrestha, and D.M. Miller. 1992. Triple helix formation by purinerich oligonucleotides targeted to the human dihydrofolate reductase promoter. Nucleic Acids Res 20: 1777-84.

Casey, B.P. and P.M. Glazer. 2001. Gene targeting via triple-helix formation. Prog Nucleic Acid Res Mol Biol 67: 163-92.

Chan, P.P. and P.M. Glazer. 1997. Triplex DNA: fundamentals, advances, and potential applications for gene therapy. $J$ Mol Med 75: 267-82.

Cheng, A.J., J.C. Wang, and M.W. Van Dyke. 1998. Self-association of G-rich oligodeoxyribonucleotides under conditions promoting purine-motif triplex formation. Antisense Nucleic Acid Drug Dev 8: 215-25.

Cherny, D.Y., B.P. Belotserkovskii, M.D. Frank-Kamenetskii, M. Egholm, O. Buchardt, R.H. Berg, and P.E. Nielsen. 1993. DNA unwinding upon strand-displacement binding of a thymine-substituted polyamide to double-stranded DNA. Proc Natl Acad Sci U S A 90: 1667-70.

Demidov, V., M.D. Frank-Kamenetskii, M. Egholm, O. Buchardt, and P.E. Nielsen. 1993. Sequence selective double strand DNA cleavage by peptide nucleic acid (PNA) targeting using nuclease S1. Nucleic Acids Res 21: 2103-7.

Demidov, V.V., E. Protozanova, K.I. Izvolsky, C. Price, P.E. Nielsen, and M.D. FrankKamenetskii. 2002. Kinetics and mechanism of the DNA double helix invasion by pseudocomplementary peptide nucleic acids. Proc Natl Acad Sci U S A 99: 5953-8.

Faucon, B., J.L. Mergny, and C. Helene. 1996. Effect of third strand composition on the triple helix formation: purine versus pyrimidine oligodeoxynucleotides. Nucleic Acids Res 24: 3181-8.

Felsenfeld, G. and A. Rich. 1957. Studies on the formation of two- and three-stranded polyribonucleotides. Biochim Biophys Acta 26: 457-68.

Francois, J.C., J. Lacoste, L. Lacroix, and J.L. Mergny. 2000. Design of antisense and triplex-forming oligonucleotides. Methods Enzymol 313: 74-95.

Frank-Kamenetskii, M.D. and S.M. Mirkin. 1995. Triplex DNA structures. Annu Rev Biochem 64: 65-95.

Gee, J.E., S. Blume, R.C. Snyder, R. Ray, and D.M. Miller. 1992. Triplex formation prevents Sp1 binding to the dihydrofolate reductase promoter. J Biol Chem 267: 11163-7.

Giovannangeli, C. and C. Helene. 1997. Progress in developments of triplex-based strategies. Antisense Nucleic Acid Drug Dev 7: 413-21.

Goni, J.R., X. de la Cruz, and M. Orozco. 2004. Triplex-forming oligonucleotide target sequences in the human genome. Nucleic Acids Res 32: 354-60.

Guianvarc'h, D., R. Benhida, J.L. Fourrey, R. Maurisse, and J.S. Sun. 2001. Incorporation of a novel nucleobase allows stable oligonucleotide-directed triple helix formation at the target sequence containing a purine.pyrimidine interruption. Chem Commun (Camb): 1814-5. 
Huang, C.Y., G. Bi, and P.S. Miller. 1996. Triplex formation by oligonucleotides containing novel deoxycytidine derivatives. Nucleic Acids Res 24: 2606-13.

Husler, P.L. and H.H. Klump. 1995. Prediction of pH-dependent properties of DNA triple helices. Arch Biochem Biophys 317: 46-56.

Jing, N., W. Xiong, Y. Guan, L. Pallansch, and S. Wang. 2002. Potassium-dependent folding: a key to intracellular delivery of G-quartet oligonucleotides as HIV inhibitors. Biochemistry 41: 5397-403.

Kaihatsu, K., R.H. Shah, X. Zhao, and D.R. Corey. 2003. Extending recognition by peptide nucleic acids (PNAs): binding to duplex DNA and inhibition of transcription by tailclamp PNA-peptide conjugates. Biochemistry 42: 13996-4003.

Kool, E.T. 1996. Circular oligonucleotides: new concepts in oligonucleotide design. Annu Rev Biophys Biomol Struct 25: 1-28.

-. 1997. Preorganization of DNA: Design Principles for Improving Nucleic Acid Recognition by Synthetic Oligonucleotides. Chem Rev 97: 1473-1488.

Kukreti, S., J.S. Sun, D. Loakes, D.M. Brown, C.H. Nguyen, E. Bisagni, T. Garestier, and C. Helene. 1998. Triple helices formed at oligopyrimidine*oligopurine sequences with base pair inversions: effect of a triplex-specific ligand on stability and selectivity. Nucleic Acids Res 26: 2179-83.

Lavelle, L. and J.R. Fresco. 1995. UV spectroscopic identification and thermodynamic analysis of protonated third strand deoxycytidine residues at neutrality in the triplex $\mathrm{d}(\mathrm{C}(+)-\mathrm{T}) 6:[\mathrm{d}(\mathrm{A}-\mathrm{G}) 6 . \mathrm{d}(\mathrm{C}-\mathrm{T}) 6]$; evidence for a proton switch. Nucleic Acids Res 23: 2692-705.

Le Doan, T., L. Perrouault, D. Praseuth, N. Habhoub, J.L. Decout, N.T. Thuong, J. Lhomme, and C. Helene. 1987. Sequence-specific recognition, photocrosslinking and cleavage of the DNA double helix by an oligo-[alpha]-thymidylate covalently linked to an azidoproflavine derivative. Nucleic Acids Res 15: 7749-60.

Lee, J.S., M.L. Woodsworth, L.J. Latimer, and A.R. Morgan. 1984. Poly(pyrimidine) . poly(purine) synthetic DNAs containing 5-methylcytosine form stable triplexes at neutral pH. Nucleic Acids Res 12: 6603-14.

Lohse, J., O. Dahl, and P.E. Nielsen. 1999. Double duplex invasion by peptide nucleic acid: a general principle for sequence-specific targeting of double-stranded DNA. Proc Natl Acad Sci U S A 96: 11804-8.

Maher, L.J., 3rd, B. Wold, and P.B. Dervan. 1989. Inhibition of DNA binding proteins by oligonucleotide-directed triple helix formation. Science 245: 725-30.

McDowell, J.A. and D.H. Turner. 1996. Investigation of the structural basis for thermodynamic stabilities of tandem GU mismatches: solution structure of (rGAGGUCUC)2 by two-dimensional NMR and simulated annealing. Biochemistry 35: 14077-89.

Mills, M., P.B. Arimondo, L. Lacroix, T. Garestier, C. Helene, H. Klump, and J.L. Mergny. 1999. Energetics of strand-displacement reactions in triple helices: a spectroscopic study. J Mol Biol 291: 1035-54.

Mills, M., P.B. Arimondo, L. Lacroix, T. Garestier, H. Klump, and J.L. Mergny. 2002. Chemical modification of the third strand: differential effects on purine and pyrimidine triple helix formation. Biochemistry 41: 357-66.

Moser, H.E. and P.B. Dervan. 1987. Sequence-specific cleavage of double helical DNA by triple helix formation. Science 238: 645-50.

Nadal, A., R. Eritja, T. Esteve, and M. Pla. 2005. "Parallel" and "antiparallel tail.clamps" increase the efficiency of triplex formation with structured DNA and RNA targets. Chem Bio Chem 6: 1034-1042.

Nielsen, P.E. 1993. Peptide nucleic acid (PNA): a model structure for the primordial genetic material? Orig Life Evol Biosph 23: 323-7.

Nielsen, P.E., M. Egholm, R.H. Berg, and O. Buchardt. 1991. Sequence-selective recognition of DNA by strand displacement with a thymine-substituted polyamide. Science 254: $1497-500$. 
Obika, S., Y. Hari, M. Sekiguchi, and T. Imanishi. 2000. Synthesis and triplex forming ability of conformationally locked oligonucleotides containing unnatural nucleobases: efficient recognition of a C.G interruption. Nucleic Acids Symp Ser: 131-2.

Peffer, N.J., J.C. Hanvey, J.E. Bisi, S.A. Thomson, C.F. Hassman, S.A. Noble, and L.E. Babiss. 1993. Strand-invasion of duplex DNA by peptide nucleic acid oligomers. Proc Natl Acad Sci U S A 90: 10648-52.

Plum, G.E. and K.J. Breslauer. 1995. Thermodynamics of an intramolecular DNA triple helix: a calorimetric and spectroscopic study of the $\mathrm{pH}$ and salt dependence of thermally induced structural transitions. J Mol Biol 248: 679-95.

Sun, J.S., T. De Bizemont, G. Duval-Valentin, T. Montenay-Garestier, and C. Helene. 1991. Extension of the range of recognition sequences for triple helix formation by oligonucleotides containing guanines and thymines. C R Acad Sci III 313: 585-90.

Vasquez, K.M., T.G. Wensel, M.E. Hogan, and J.H. Wilson. 1995. High-affinity triple helix formation by synthetic oligonucleotides at a site within a selectable mammalian gene. Biochemistry 34: 7243-51.

Vo, T., S. Wang, and E.T. Kool. 1995. Targeting pyrimidine single strands by triplex formation: structural optimization of binding. Nucleic Acids Res 23: 2937-44.

Wang, S.a.K., E.T. 1994. Recognition of single-stranded nucleic acids by triplex formation: The binding of pyrimidine-rich sequences. J. Am. Chem. Soc 116: 8857-8858. 


\section{FIGURE LEGENDS}

Table 1. List of the oligonucleotides used in this study. Column 1 lists the abbreviated name, followed by the sequence of the oligonucleotide (column 2). The abbreviation of each polypurine/polypyrimidine DNA target was given using the following criteria: length of the oligonucleotide-followed by the composition of the strand (purine or pyrimidine)-ending with the number of the exon where it is located. Interruptions in antiparallel purine-hairpins and in polypurine/polypyrimidine DNA targets are shown in bold. Polypurine/polypyrimidine DNA targets are underlined.

Figure 1. Hairpin6 specifically binds its polypyrimidine single-stranded DNA target. (A) Binding of ${ }^{32} \mathrm{P}$-polypyrimidine single-stranded DNA (10 $\mathrm{nM}$ radiolabeled 20py6) to increasing concentrations of unlabeled hairpin6 $(1-50 \mu \mathrm{M})$ upon a $16-\mathrm{h}$ incubation at $37^{\circ} \mathrm{C}$. (B) Binding of ${ }^{32} \mathrm{P}$-polypyrimidine single-stranded DNA (10 nM radiolabeled 20py6) to $1 \mu \mathrm{M}$ unlabeled hairpin6. Incubations were carried out at $37^{\circ} \mathrm{C}$ for $0.2-16$ hours. (C) Phosphorimage showing the specificity of the binding of hairpin6 to its polypyrimidine singlestranded DNA target. Competitions were performed using ${ }^{32} \mathrm{P}$-polypyrimidine single-stranded DNA (10 nM radiolabeled 20py6), $100 \mathrm{nM}$ unlabeled hairpin6 and i) unlabeled specific polypyrimidine single-stranded DNA or ii) an unlabeled non-specific strand. Incubations were carried out at $37^{\circ} \mathrm{C}$ for 0.5 hours. The unlabeled strand excess respect to the ${ }^{32} \mathrm{P}$ polypyrimidine single-stranded DNA is indicated above each lane. (D) Binding of ${ }^{32} \mathrm{P}$ polypyrimidine single-stranded DNA (10 nM radiolabeled 20py6) to $1 \mu \mathrm{M}$ unlabeled hairpin6 in the presence of increasing concentrations of $\mathrm{MgCl}_{2}$ upon a $16-\mathrm{h}$ incubation at $37^{\circ} \mathrm{C}$.

Figure 2. Hairpin6 binds its polypurine/polypyrimidine double-stranded DNA target. (A) Binding of ${ }^{32} \mathrm{P}$-hairpin6 (10 $\mathrm{nM}$ radiolabeled hairpin6) to increasing concentrations of unlabeled polypurine/polypyrimidine DNA (0.1-5 $\mu \mathrm{M}$ 20pu6/20py6 duplex) upon a 16-h

incubation at $37^{\circ} \mathrm{C}$. (B) Binding of ${ }^{32} \mathrm{P}$-hairpin6 (10 $\mathrm{nM}$ radiolabeled hairpin6) to $1 \mu \mathrm{M}$ unlabeled polypurine/polypyrimidine DNA (20pu6/20py6 duplex). Incubations were carried out at $37^{\circ} \mathrm{C}$ for $0.2-16$ hours. (C) Phosphorimage showing the ability of hairpin6 (10 nM 
radiolabeled hairpin6) to bind polypurine/polypyrimidine stretches included in DNA duplexes of several hundred bp in length (152 and $227 \mathrm{bp}$ ). (D) Binding of hairpin6 (10 nM radiolabeled hairpin6) to $0.6 \mu \mathrm{M}$ unlabeled double-stranded DNA (152 bp and $227 \mathrm{bp}$ in length) containing the polypurine/polypyrimidine target in the presence of increasing concentrations of $\mathrm{MgCl}_{2}$ after 16 -h of incubation at $37^{\circ} \mathrm{C}$.

Figure 3. Binding of purine-hairpin to double-stranded DNA occurs by triplex formation with the polypyrimidine strand, causing displacement of the polypurine strand. (A) Binding of radiolabeled polypurine/polypyrimidine double-stranded DNA (10 nM radiolabeled 20pu6/20py6 duplex) to $0.1 \mu \mathrm{M}$ unlabeled hairpin6. Lane 1, Radiolabeled polypurine/polypyrimidine duplex; Lane 2, ${ }^{32} \mathrm{P}$-polypurine $/{ }^{32} \mathrm{P}$-polypyrimidine duplex plus unlabeled hairpin6; Lane 3, polypurine/ ${ }^{32} \mathrm{P}$-polypyrimidine duplex plus unlabeled hairpin6; Lane 4, ${ }^{32} \mathrm{P}$-polypurine/polypyrimidine duplex plus unlabeled hairpin6; Lane 5, ${ }^{32} \mathrm{P}$-polypurine single-stranded DNA (10 nM radiolabeled 20pu6); Lane 6, ${ }^{32} \mathrm{P}$-polypyrimidine single-stranded DNA (10 nM radiolabeled 20py6); Lane 7, ${ }^{32}$ P-polypyrimidine single-stranded DNA plus 0.1 $\mu \mathrm{M}$ unlabeled hairpin6. Incubations were performed at $37^{\circ} \mathrm{C}$ for 16 hours. Triplexes (band a), duplexes (band b), single-stranded DNA targets (band c) and purine-hairpins are indicated by arrowheads. (B) Diagram showing the displacement of the polypurine strand upon triplex formation between hairpin6 and the polypyrimidine strand of the polypurine/polypyrimidine duplex.

Figure 4. Effect of the reverse-Hoogsteen domain on the binding of hairpin6 to its single-stranded DNA target. (A) Quantitative analysis of binding of ${ }^{32} \mathrm{P}$-polypyrimidine singlestranded DNA (10 $\mathrm{nM}$ radiolabeled 20py6) to increasing concentrations $(0.01-1 \mu \mathrm{M})$ of unlabeled hairpin6 (black circle), hairpin6-scrambled (black square) or Watson-Crick6 (black triangle). Incubations were carried out at $37^{\circ} \mathrm{C}$ for 16 hours. (B) a Melting transition temperatures $(T m)$ and free energies $(\Delta G)$ at $\mathrm{pH} 7.2$.

a Conditions: $40 \mathrm{mM} \mathrm{MgCl} 2,100 \mathrm{mM} \mathrm{NaCl}, 50 \mathrm{mM}$ HEPES pH 7.2 and $2 \mu \mathrm{M}$ each oligonucleotide strand. ${ }^{b}$ Error in $T m$ values and in free energies are estimated at $+/-1.0^{\circ} \mathrm{C}$ and $+/-10 \%$, respectively. 
Figure 5. Effect of the reverse-Hoogsteen domain on the binding of hairpin6 to its double-stranded DNA target. (A) Binding of polypurine $/{ }^{32} \mathrm{P}$-polypyrimidine double-stranded DNA (10 nM radiolabeled 20pu6/20py6 duplex) to $0.1 \mu \mathrm{M}$ of unlabeled hairpin6, hairpin6scrambled, Watson-Crick6 or TFO6. Incubations were performed at $37^{\circ} \mathrm{C}$ for 16 hours. (B) Binding of ${ }^{32} \mathrm{P}$-hairpin6 (10 $\mathrm{nM}$ radiolabeled hairpin6) or ${ }^{32} \mathrm{P}$-hairpin6-scrambled (10 $\mathrm{nM}$ radiolabeled hairpin6-scrambled), to increasing concentrations of unlabeled double-stranded DNA (20 bp and $49 \mathrm{bp}$ in length) containing the polypurine/polypyrimidine target $(0.5-5 \mu \mathrm{M}$ 20pu6/20py6 or 49pu6/49py6 duplex). Incubations were carried out at $37^{\circ} \mathrm{C}$ for 16 hours.

Figure 6. Effect of an interruption in the polypurine/polypyrimidine sequence on triplex formation with hairpin1. (A) Quantitative analysis of binding of ${ }^{32} \mathrm{P}$-polypyrimidine single-stranded DNA (10 nM radiolabeled 28py1) to increasing concentrations $(0.01-1 \mu \mathrm{M})$ of unlabeled hairpin1-AA (black circle), hairpin-CG (black triangle) or hairpin1-GG (black square). Incubations were carried out at $37^{\circ} \mathrm{C}$ for 16 hours. (B) ${ }^{a}$ Melting transition temperatures $(T m)$ and free energies $(\Delta G)$ at $\mathrm{pH}$ 7.2. (C) Binding of ${ }^{32} \mathrm{P}$-hairpin1-AA, ${ }^{32} \mathrm{P}$ hairpin1-CG or ${ }^{32} \mathrm{P}$ - hairpin1-GG (10 nM radiolabeled hairpin1) to increasing concentrations of unlabeled polypurine/polypyrimidine double-stranded DNA (0.1-1 $\mu \mathrm{M}$ 28pu1/28py1 duplex). Incubations were performed at $37^{\circ} \mathrm{C}$ for 16 hours. (D) T.A*A triplex in antiparallel triplexes. When $T$ is replaced by $G$, a similar base triplex could be formed using the 6-keto and $\mathrm{N}-1-\mathrm{H}$ groups of $\mathrm{G}$ instead of the $4-$ keto and $\mathrm{N}-1-\mathrm{H}$ of $\mathrm{T}$ ( $\mathrm{G} \cdot \mathrm{A}^{*} \mathrm{~A}$ triplex).

${ }^{\mathrm{a} C}$ Conditions: $40 \mathrm{mM} \mathrm{MgCl}, 100 \mathrm{mM} \mathrm{NaCl}, 50 \mathrm{mM}$ HEPES pH 7.2 and $2 \mu \mathrm{M}$ each oligonucleotide strand. ${ }^{b}$ Error in $T m$ values and in free energies are estimated at $+/-1.0^{\circ} \mathrm{C}$ and $+/-10 \%$, respectively.

Figure 7. Recognition of polypurine/polypyrimidine sequence by extended and tailed purine-hairpins. (A) Binding of ${ }^{32} \mathrm{P}$-polypyrimidine single-stranded DNA (10 nM radiolabeled 33py6) to increasing concentrations $(0.01-1 \mu \mathrm{M})$ of unlabeled tail-hairpin6 or hairpin6-20. Incubations were carried out at $37^{\circ} \mathrm{C}$ for 16 hours. (B) ${ }^{a}$ Melting transition temperatures $(\mathrm{Tm})$ and free energies $(\Delta G)$ at $\mathrm{pH}$ 7.2. (C) Binding of ${ }^{32} \mathrm{P}$-tail-hairpin6 or ${ }^{32} \mathrm{P}$-hairpin6-20 (10 $\mathrm{nM}$ 
radiolabeled hairpin) to $1 \mu \mathrm{M}$ unlabeled polypurine/polypyrimidine double-stranded DNA (33pu6/33py6 duplex). Incubations were performed at $37^{\circ} \mathrm{C}$ for $0.2-16$ hours.

${ }^{\mathrm{a} C}$ Conditions: $40 \mathrm{mM} \mathrm{MgCl}, 100 \mathrm{mM} \mathrm{NaCl}, 50 \mathrm{mM}$ HEPES pH 7.2 and $2 \mu \mathrm{M}$ each oligonucleotide strand. ${ }^{b}$ Error in $\mathrm{Tm}$ values and in free energies are estimated at $+/-1.0^{\circ} \mathrm{C}$ and $+/-10 \%$, respectively. 


\section{Table 1}

\begin{tabular}{|c|c|}
\hline Name & Sequence \\
\hline \multicolumn{2}{|l|}{ EXON 6.} \\
\hline Hairpin6 & $5^{\prime}$-GGAAAAAGGAGGA- $(\mathrm{T}){ }_{5}$-AGGAGGAAAAAGG-3' \\
\hline Hairpin6-scrambled & $5^{\prime}$-AGGAAGGAAGGAA- $(\mathrm{T})_{5}$-AGGAGGAAAAAGG-3' \\
\hline Watson-Crick6 & $5^{\prime}-$ AGGAGGAAAAAGG-3' \\
\hline TFO6 & 3'-AGGAGGAAAAAGG-5' \\
\hline Hairpin6-20 & $5^{\prime}$-GAAAAAAGGAAAAAGGAGGA- $(\mathrm{T})$ 5-AGGAGGAAAAAGGAAAAAAG-3' \\
\hline Tail-hairpin6 & $5 '$-GGAAAAAGGAGGA- $(\mathrm{T})_{5}$-AGGAGGAAAAAGGCATCAAG -3 ' \\
\hline 20 pu6 & 5'-GAAGTCCAGGAGGAAAAAGG-3' \\
\hline 20 py6 & 3'-CTTCAGGTCCTCCTTTTTCC-5' \\
\hline 33pu6 & 5 '-TCTGAAGTCCAGGAGGAAAAAGGCATCAAGTAT-3' \\
\hline 33py6 & 3'-AGACTTCAGGTCCTCCTTTTTCCGTAGTTCATA-5' \\
\hline 49pu6 & $5^{\prime}$-AGGAGGAAAAAGGCATCAAGTATAAATTTGAAGTCTATGAGAAGAAAGG-3' \\
\hline 49py6 & 3'-ТССТССТTTTTCCGTAGTTCATATTTAAACTTCAGATACTCTTCTTTCC-5' \\
\hline \multicolumn{2}{|l|}{ EXON 1.} \\
\hline Hairpin1-AA & $5^{\prime}-$ AGAGGAAAGAA- $(\mathrm{T})_{5}-\mathrm{AAGAAAGGAGA}-3^{\prime}-3^{\prime}$ \\
\hline Hairpin1-GG & $5^{\prime}-$ AGAGGGAAGAA- $(\text { T })_{5}$-AAGAAGGGAGA-3'-3' \\
\hline Hairpin1-CG & $5^{\prime}-$ AGAGGGAAGAA- $(\mathrm{T})_{5}-\mathrm{AAGAACGGAGA}-3^{\prime}-3^{\prime}$ \\
\hline $28 p u 1$ & $5^{\prime}$-AGAATATGGGCATCGGCAAGAACGGAGA-3' \\
\hline $28 p y 1$ & 3'-TCTTATACCCGTAGCCGTTCTTGCCTCT-5' \\
\hline
\end{tabular}


Figure 1

A

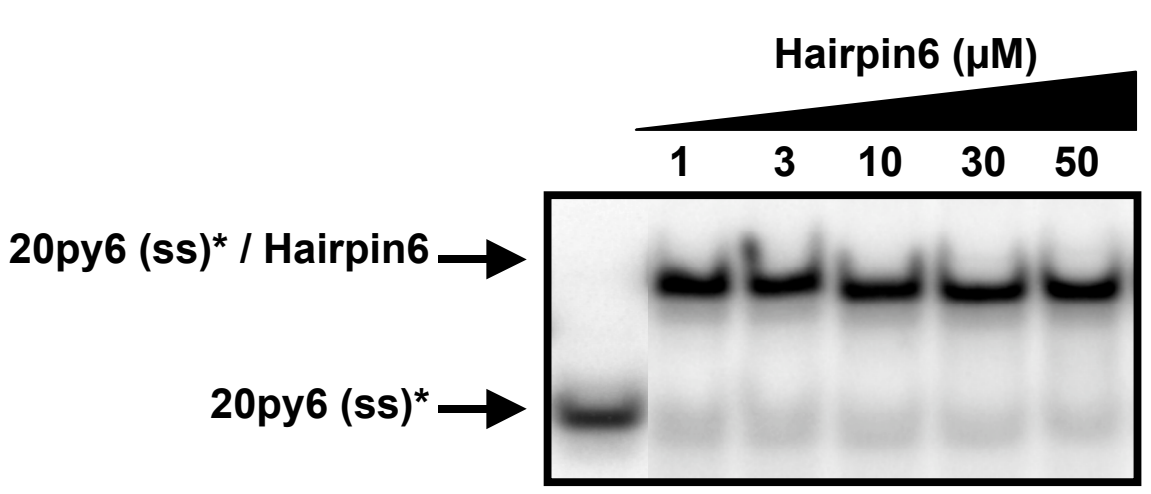

Time of

B
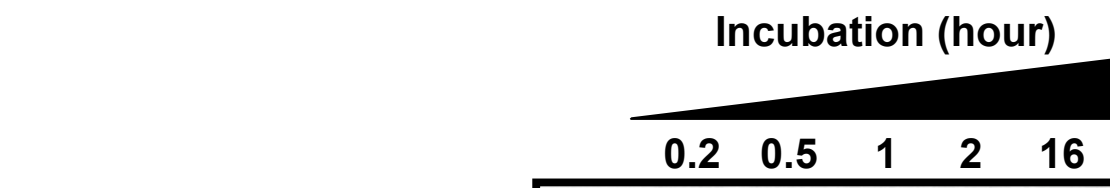

20 py6 (ss)* I Hairpin6 $\rightarrow$
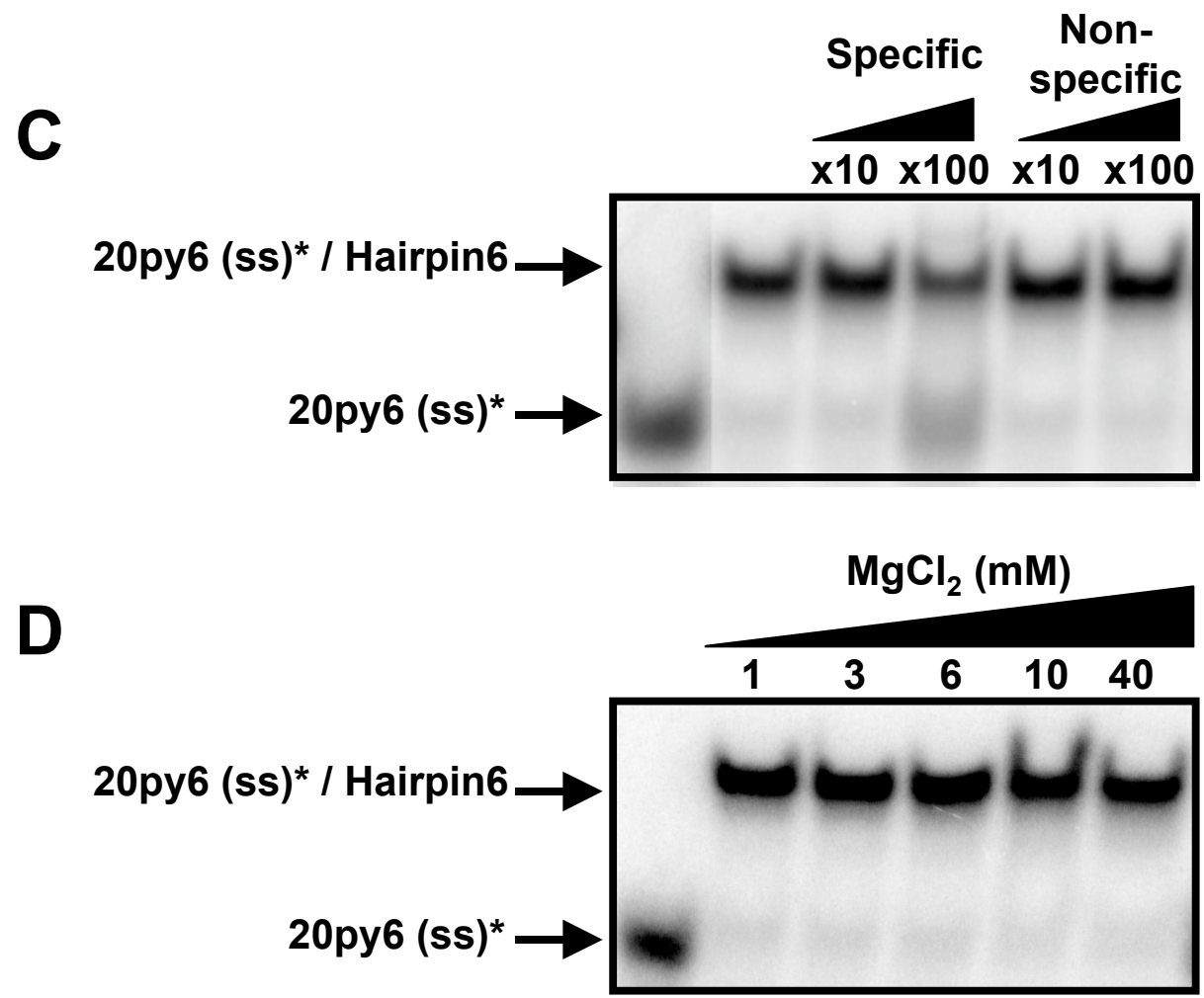
Figure 2

A

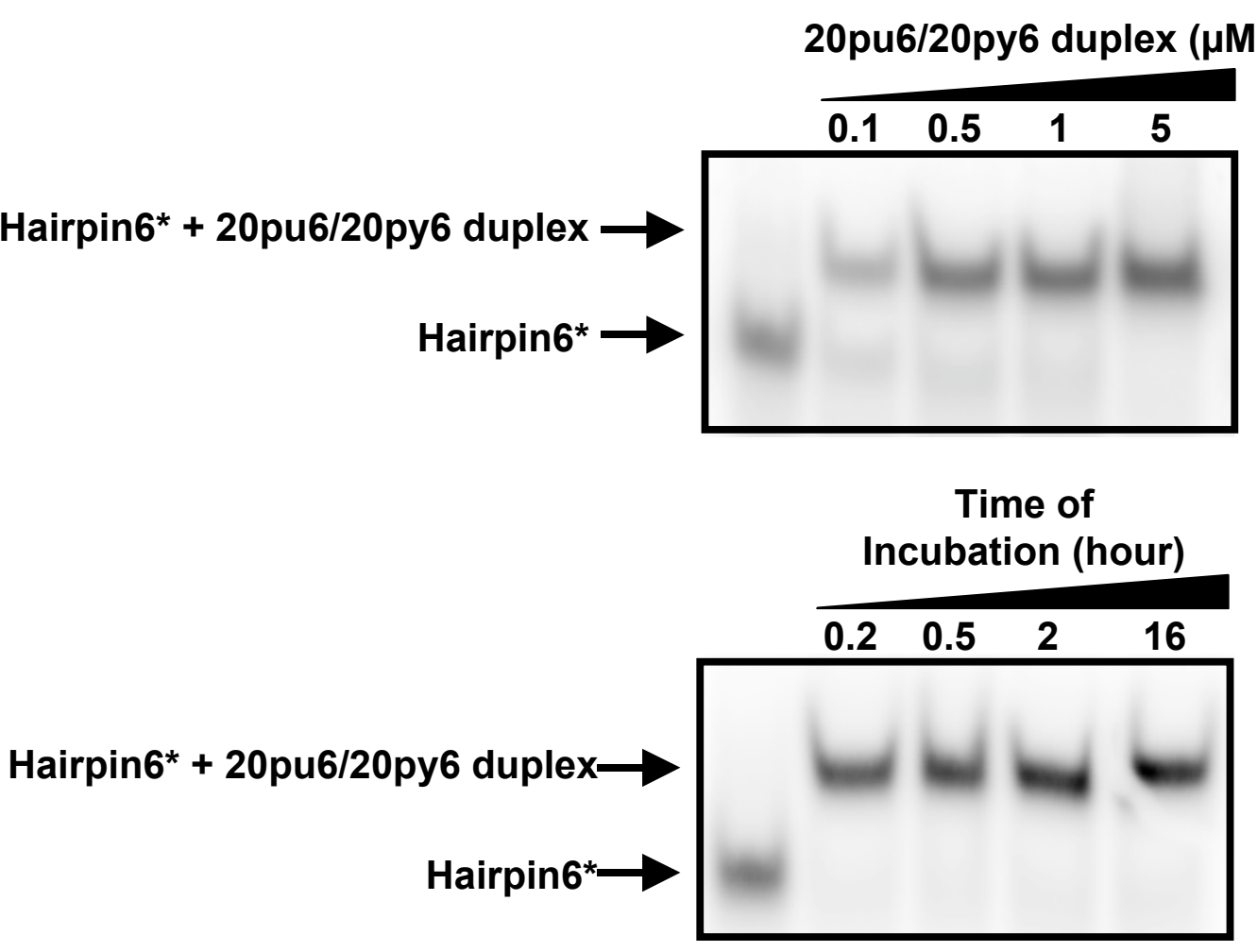

C

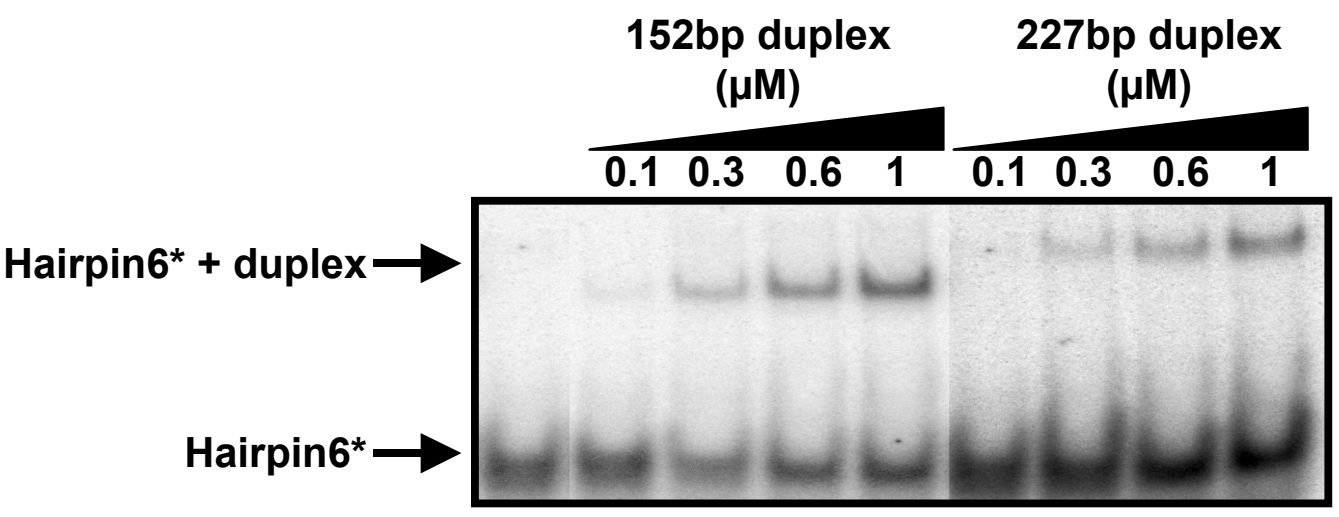

D

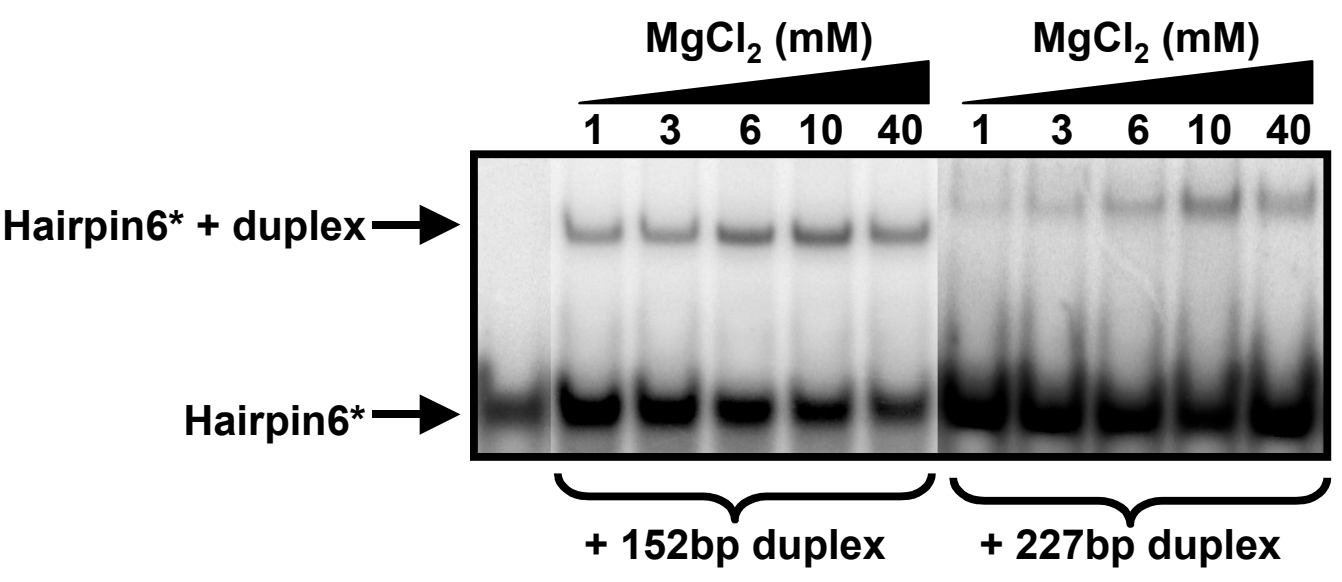


Figure 3

\section{A}

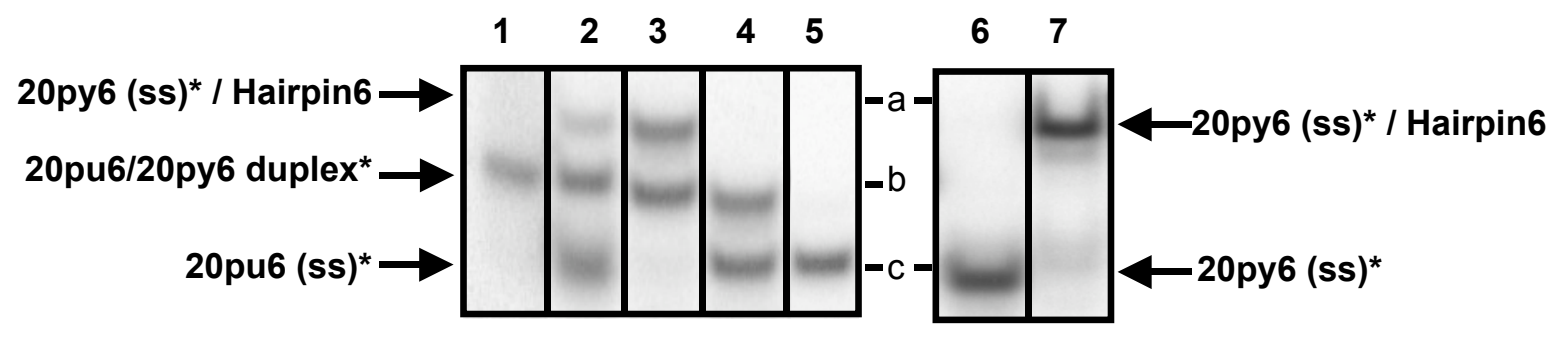

B

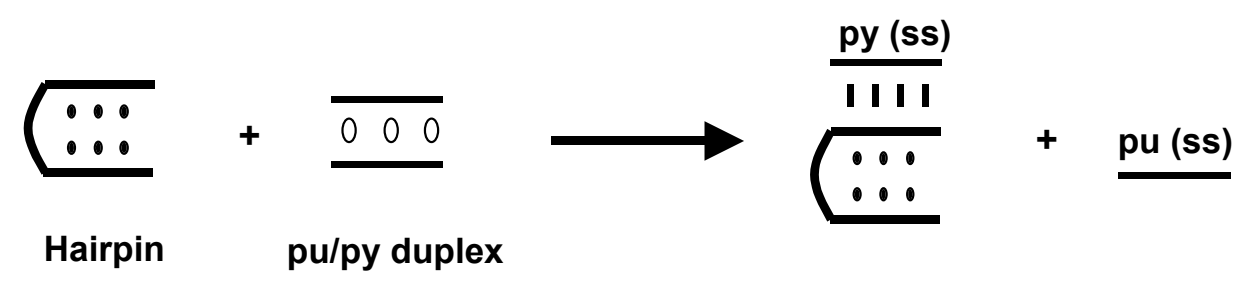




\section{Figure 4}

\section{A}
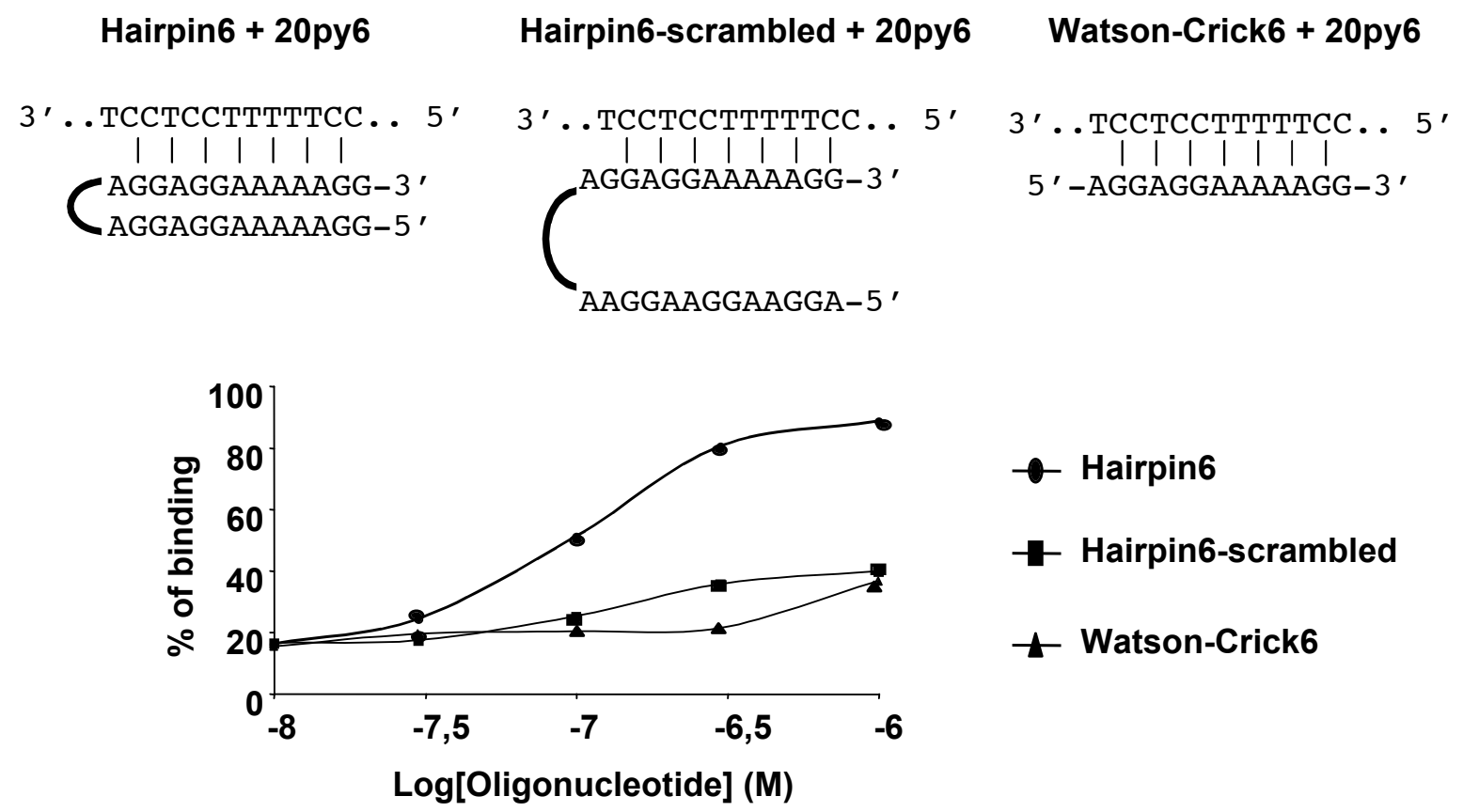

$\rightarrow$ Hairpin6

- Hairpin6-scrambled

$\mp$ Watson-Crick6

B

\begin{tabular}{lcc}
\hline Complex & $\operatorname{Tm}\left({ }^{\circ} \mathrm{C}\right)^{\mathrm{b}}$ & $\Delta G(\mathrm{kcal} / \mathrm{mol}){ }^{\mathrm{b}}$ \\
\hline Hairpin6 + 33py6 & 63.3 & -18.4 \\
Hairpin6-scrambled + 33py6 & 55.1 & -12.9 \\
Watson-Crick6 + 33py6 & 57.7 & -14.6 \\
\hline
\end{tabular}


Figure 5

A

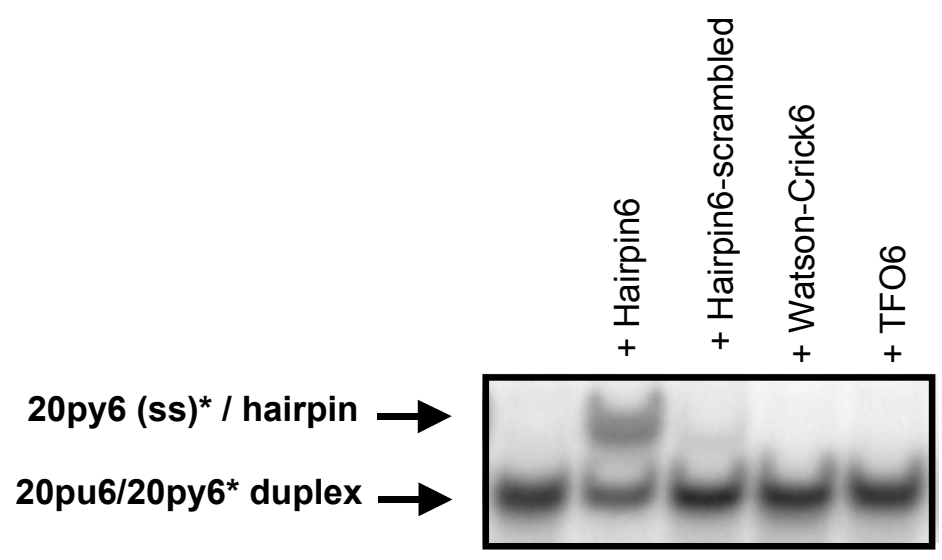

B

20pu6/20py6 49pu6/49py6 20pu6/20py6 49pu6/49py6 duplex $(\mu \mathrm{M})$ duplex $(\mu \mathrm{M})$ duplex $(\mu \mathrm{M})$ duplex $(\mu \mathrm{M})$

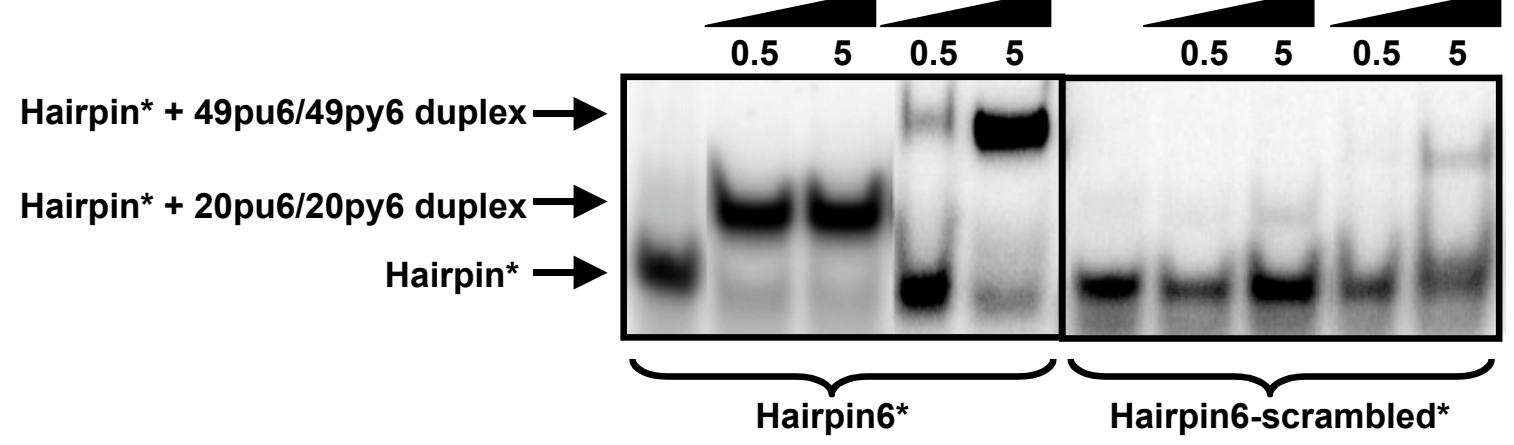




\section{Figure 6}

A

Hairpin1-AA + 28py1 Hairpin1-GG + 28py1 Hairpin1-CG + 28py1

3' . .TTCTTGCСTCT. . 5' | | | | | | |

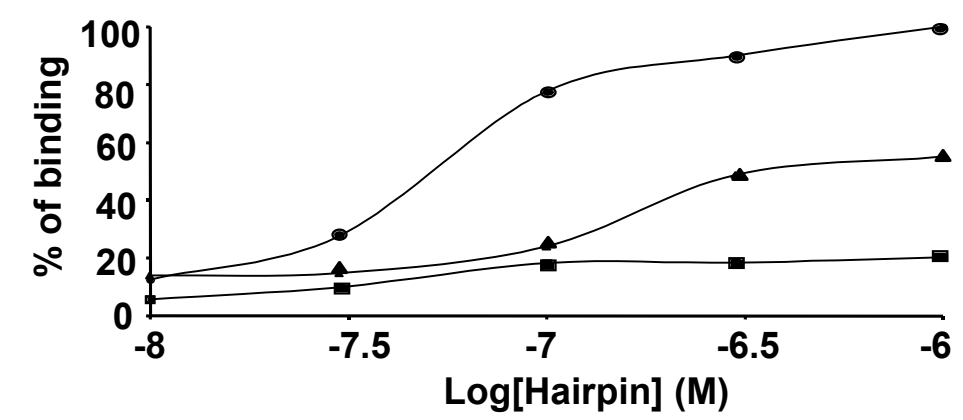

B

\begin{tabular}{ccc}
\hline Complex & $\operatorname{Tm}\left({ }^{\circ} \mathrm{C}\right)^{\mathrm{b}}$ & $\Delta G(\mathrm{kcal} / \mathrm{mol}){ }^{\mathrm{b}}$ \\
\hline Hairpin1-AA + 28py1 & 45.5 & -10.8 \\
Hairpin1-CG + 28py1 & 45.4 & -10.5 \\
Hairpin1-GG + 28py1 & 40.7 & -9.3 \\
\hline
\end{tabular}

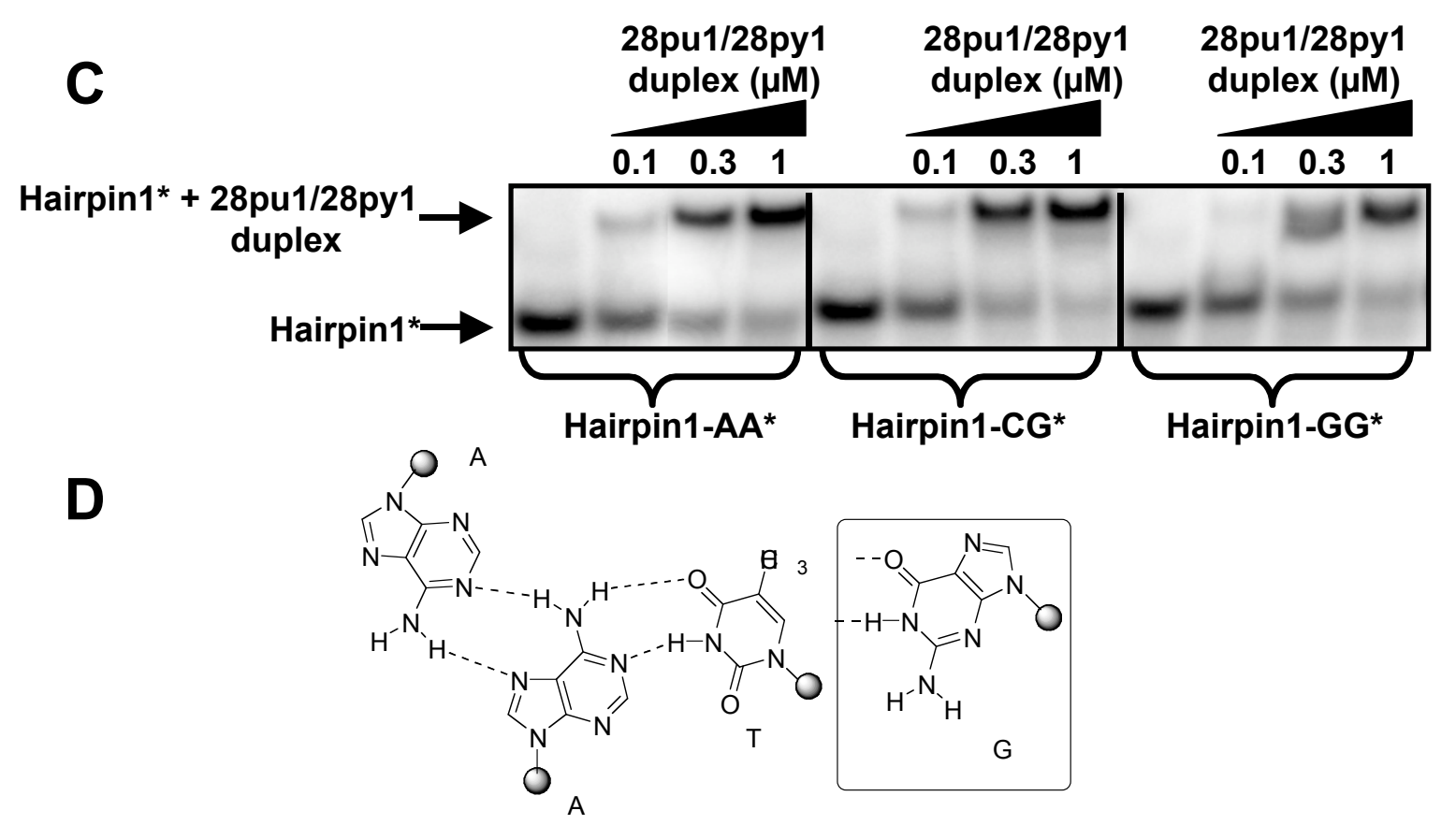




\section{Figure 7}

A

Tail-hairpin $6+33 p y 6$

Hairpin6-20 + 33py 6

3' . TCCTCCTTTTTCCGTAGTTC. . 5

3' . . TCCTCCTTTTTCCGTAGTTC. . 5'

| | | | | | | | | |

AGGAGGAAAAAGGCATCAAG-3'

AGgAGgAAAAAGGAAAAAAG-3 '

AGGAGGAAAAAGG-5'

AGGAGGAAAAAGGAAAAAAG-5

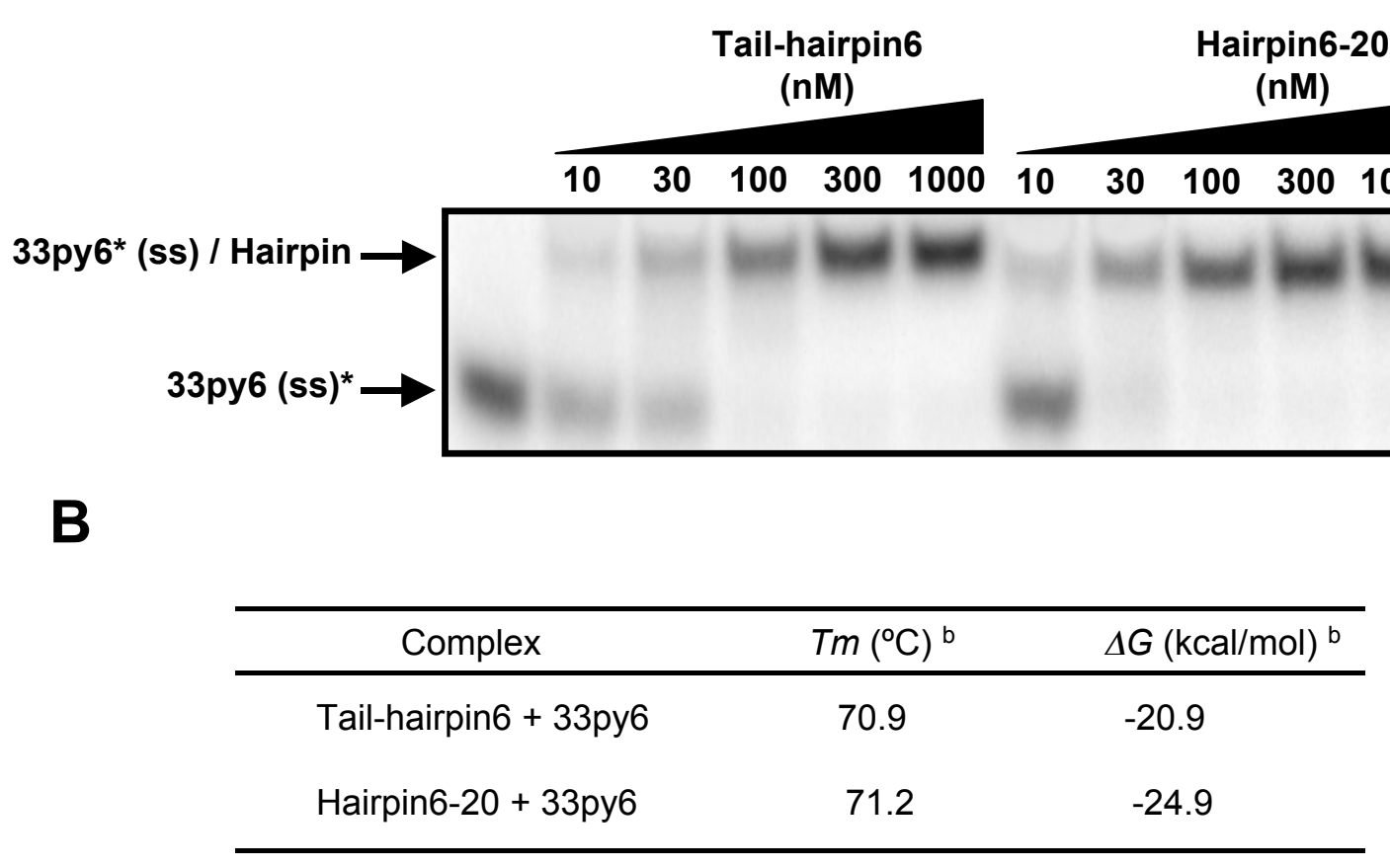

C

Time of Incubation (hour)
Time of Incubation (hour)

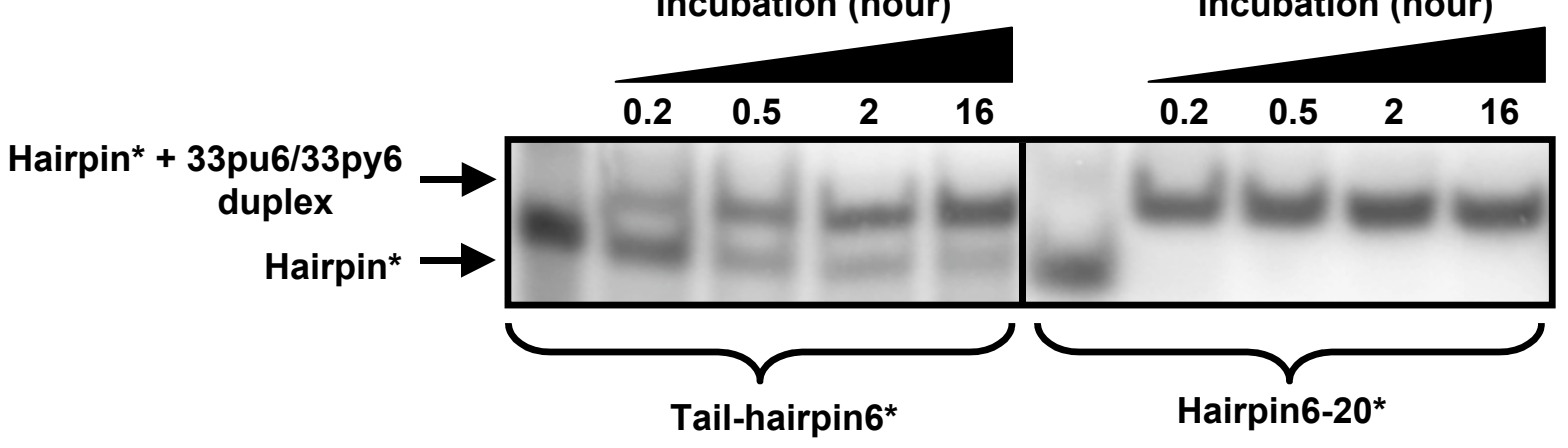

